\title{
IFRS 17: ПОСЛЕДУЮЩИЕ ИЗМЕРЕНИЯ СТРАХОВЫХ КОНТРАКТОВ
}

\author{
Kulustayeva A.M. \\ Phd student of the University Narhoz \\ Almaty, the Republic of Kazakhstan \\ E-mail: mishell_a@mail.ru ORCID ID 0000-0002-2686-6617
}

\section{IFRS 17: SUBSEQUENT MEASUREMENTS OF INSURANCE CONTRACTS}

\begin{abstract}
According to IFRS 17, insurance contracts can be assessed using a common model. Upon initial recognition, a company must evaluate a group of contracts on the total amount of future cash flows and contract margins.

Cash flows should be calculated with an adjustment reflecting the cost of money over time. In addition, the financial risks associated with future cash flows should be taken into account. Risk adjustment should also take into account non-financial risks.

The subsequent assessment of the balance sheet value of a group of insurance contracts at the end of each reporting period should consist of the amount of obligations for the remaining insurance coverage and obligations for losses incurred. The first part of these obligations should include cash flows related to future services and the group's contract margin at that date. The second part of the liabilities includes cash flows that are associated with past services assigned to the group at that date.
\end{abstract}

Key words: insurance contracts, subsequent measurements, cash flows, liabilities.

Абстракт: Согласно IFRS 17 договоры страхования могут быть оченены по общей модели. При первоначальном признании компания долюна оценивать группу договоров по общей сумме величины будущих денежных потоков и контрактной маржи.

Денежные потоки должны быть рассчитаны с корректировкой, отражающей стоимость денег во времени. Кроме этого, долэны быть учтены финансовые риски, связанные с денежными потоками в будущем. Корректировка рисков должна учитывать нефинансовые риски.

Последующая оиенка балансовой стоимости группь договоров страхования на конеи каждого отчетного периода должна состоять из суммы обязательств по оставщемуся страховому покрытию и обязательств по понесенным убыткам. Первая часть этих обязательств должна включать денежные потоки, относящиеся $\kappa$ будущим услугам $u$ контрактную маржу группы на эту дату. Вторая часть обязательств включает денежные потоки, которые связаны с прошлыми услугами, отнесенными на группу на эту дату.

Ключевые слова: страховые контракты, последующие измерения, денежные потоки, обязательства.

С 2021 года вводится новый стандарт по учету договоров страхования, целью которого является повышение уровня прозрачности и сопоставимости отчетности по сравнению с действующим стандартом. IFRS-17 требует последовательного учета всех страховых контрактов на основе модели текущих измерений [1].

Основные требования к измерению в IFRS 17 сводятся к тому, что договоры страхования измеряются по денежным потокам по исполнению обязательств и по

Бухгалтерский учет и аудит
Материалы Международной практической интернет-конференции «Актуальные Проблемы Науки» 
контрактной марже. Первая составляющая - это чистая оценка будущих денежных потоков, которая учитывает финансовые риски. Оцененные с учетом вероятностей, будущие денежные потоки должны быть приведены к текущей стоимости. Премия за нефинансовые риски, которая называется корректировкой по риску, добавляется к оцененным с учетом вероятностей денежным потокам. Таким образом денежные потоки по исполнению обязательств учитывают нефинансовые риски.

Вторая составляющая, представляющая собой неполученную прибыль за оказание услуг, предусмотренных в контракте, называется контрактной маржой (CSM).

При первоначальном признании текущая стоимость будущих денежных потоков и корректировка по рискам измеряются с использованием текущих допущений. На дату представления отчетности они будут измеряться также с учетом текущих допущений.

CSM при первоначальном признании представляет собой величину доходов не отражаемых в отчете о прибылях и убытках. Три характеристики, включающие будущие денежные потоки, ставку дисконтирования и корректировку для учета риска дадут возможность найти вероятностно-взвешенную оценку денежных потоков по исполнению обязательств и контрактную маржу по договору (рисунок 1)
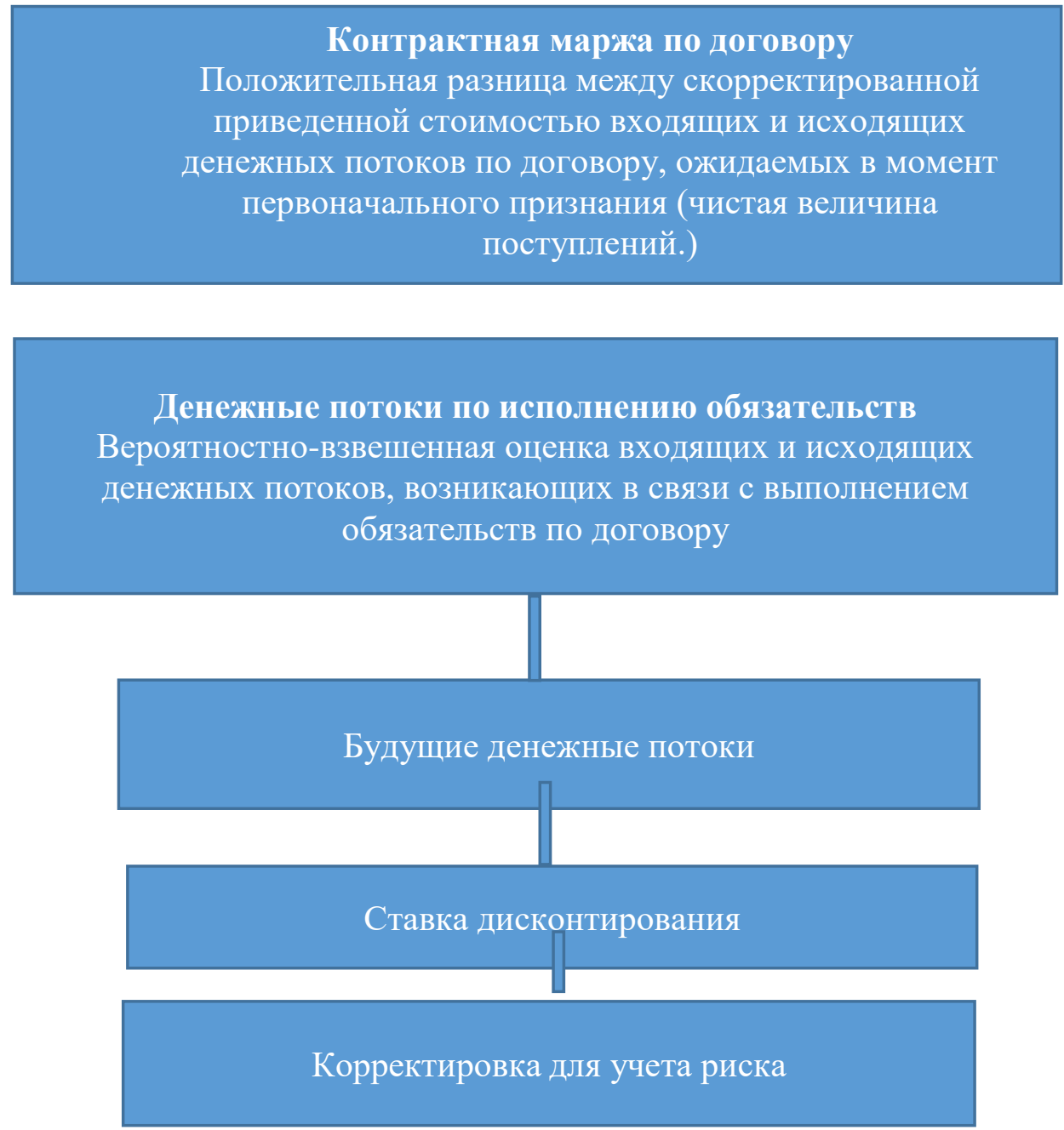

Рисунок 1 - Оченка страховых договоров при первоначальном признании Примечание: Рисунок составлен автором на основе источника [2].

Бухгалтерский учет и аудит
Материалы Международной практической интернет-конференции «Актуальные Проблемы Науки» 
Далее контрактная маржа пересчитывается с учетом временной стоимости денег и изменений, которые связаны с будущими услугами и распределенными суммами, полученными за оказанные услуги и отражается в отчете о прибылях и убытках.

Изменения в денежных потоках по исполнению обязательств и контрактной марже отражаются в прибылях и убытках следующим образом (рисунок 2).
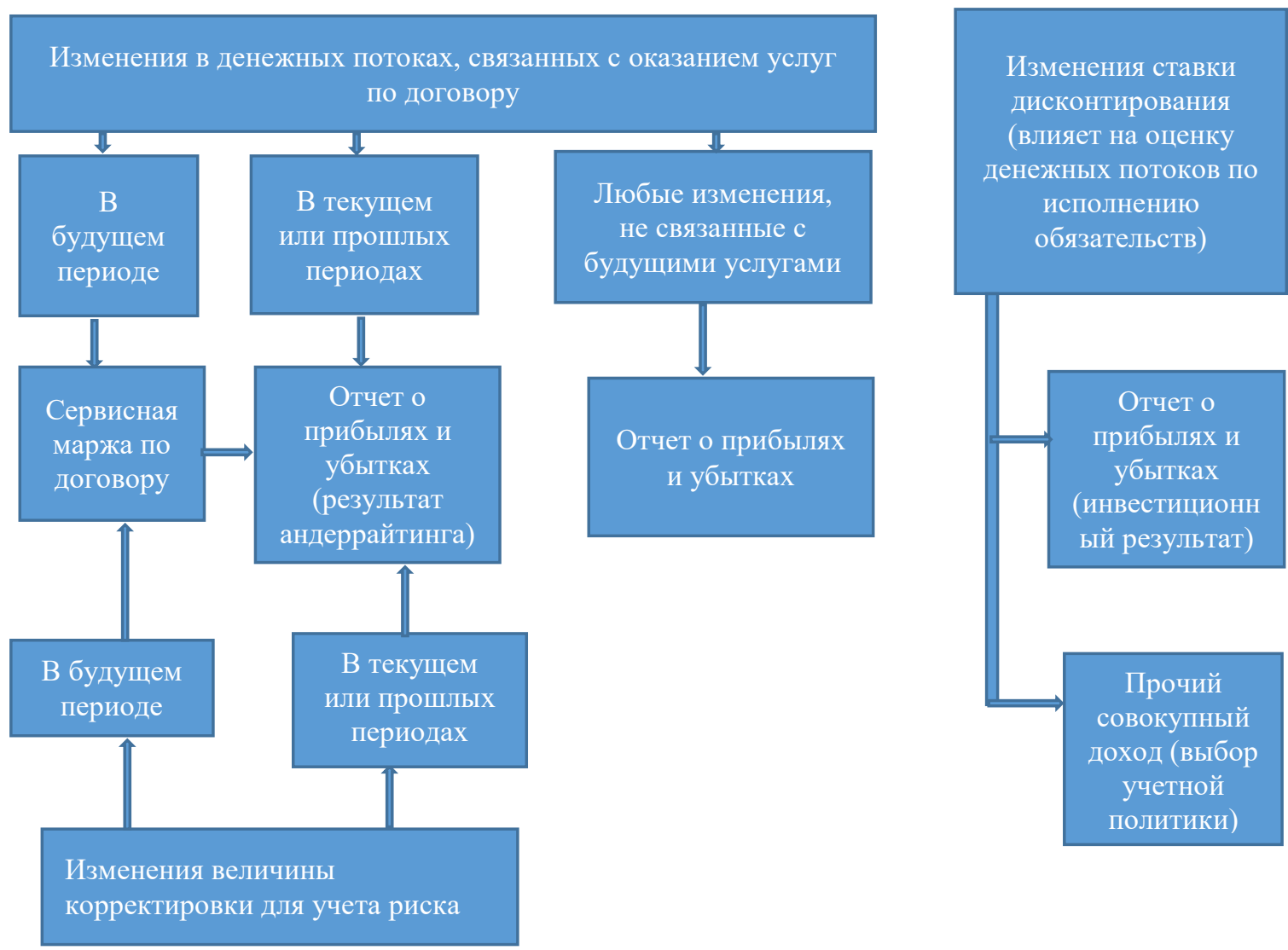

Рисунок 2- Признание изменений по договорам страхования Примечание: Рисунок составлен автором на основе источника [3].

Как видно из рисунка 2, контрактная маржа представляет собой результат оказания страховых услуг, а изменения в денежных потоках и корректировка по риску относятся на текущие и прошлые услуги. Любые изменения, не связанные с будущими услугами, например, доходы на финансовые активы или любые другие активы, будут отражаться как инвестиционный доход. Изменение временной стоимости денег и финансового риска по страховому договору необходимо отражать в качестве страхового дохода или расхода.

Необходимо отметить, что денежные потоки и изменения в корректировке по риску, относящиеся на будущие услуги, влияют на контрактную маржу в том периоде, когда возникают изменения, снижая ее ниже нуля. Поэтому эти изменения не признаются в отчете о прибылях и убытках.

Финансовый же доход в результате разделения эффектов от изменения временной стоимости денег и финансового риска признается в отчете о прибылях и убытках и в прочем совокупном доходе.

Последующие измерения CSM связаны с тем, что накопленные проценты отражаются как часть ее начальной балансовой величины.

Бухгалтерский учет и аудит
Материалы Международной практической интернет-конференции «Актуальные Проблемы Науки» 
Далее она меняется с учетом изменения денежных потоков и корректировки по рискам, связанных с будущими услугами. Эти изменения могут уменьшить или увеличить контрактную маржу, но она не может быть меньше нуля. Затем контрактная маржа распределяется и признается как оказанные за этот период страховые услуги в прибылях и убытках.

Чтобы отразить проценты частью начальной балансовой величины CSM, необходимо учесть ставку дисконтирования на дату начала действия договора, то есть взять начальную ставку, которая применяется к номинальным денежным потокам, не меняющимся в зависимости от дохода на базовые элементы.

Далее CSM необходимо откорректировать с учетом изменений, которые будут относится на будущие услуги. Это будут изменения в текущей стоимости, относящиеся на будущие услуги денежных потоков, которые будут определены с использованием первоначальной ставки дисконтирования, которая применяется в отношении этих денежных потоков по исполнению обязательств. И это будут изменения в корректировке по риску, которые также относятся на будущие услуги.

Балансовая величина CSM далее распределяется для отражения в прибылях и убытках оказанных за текущий период страховых услуг. Распределение производится на основе элементов покрытия, которые отражают сумму предоставленных страховых возмещений и ожидаемый период покрытия.

Далее рассмотрим корректировки контрактной маржи. Где признаются эти корректировки? Накопленные проценты признаются в прибылях и убытках в качестве страхового финансового дохода или расхода. Изменения, связанные с будущими услугами, представляют собой также денежные потоки по исполнению обязательств и поэтому не отражаются в прибылях и убытках. Распределение CSM снижает балансовую величину CSM, что показывается в прибылях и убытках частью результата оказания финансовых услуг [4].

Обязательства на оставшийся период покрытия представляют собой обязанность проверить и выплатить возмещение по страховому случаю, который пока не наступил, но, согласно ожиданиям, наступит в течение периода покрытия. Что происходит с убыточной составляющей? Она корректируется с учетом увеличения или уменьшения оценок, которые относятся к будущим услугам.

Эти оценки состоят из дисконтированных величин денежных потоков, пересмотренных на дату первоначального признания и изменения в корректировке по риску, которые также относятся к будущим услугам.

Далее последующие изменения в денежных потоках по исполнению обязательств на систематической основе распределяются на убыточную составляющую и неубыточную.

Неубыточную составляющую можно назвать «обязательством для оставшегося периода покрытия за минусом убыточной составляющей».

Корректировки, о которых говорилось ранее, могут привести к возникновению убыточной составляющей, которая будет равна нулю в конце периода покрытия.

Если происходит уменьшение денежных потоков по исполнению обязательств на оставшийся период покрытия, превышающее убыточную составляющую, то оно распределяется на убыточную составляющую, чтобы свести ее к нулю. А остаток величины уменьшения формирует собой контрактную маржу.

Заключение. IFRS 17 предусматривает отражение изменений в денежных потоках по страховым договорам следующим образом:

Бухгалтерский учет и аудит
Материалы Международной практической интернет-конференции «Актуальные Проблемы Науки» 
- если изменения связаны с услугами в текущем или прошлом периодах, - они отражаются в отчете о прибылях и убытках;

- если изменения относятся к будущим услугам- за счет контрактной маржи по договору, включенной в балансовую величину;

- любые изменения, не связанные с будущими услугами- в составе отчета о прибылях и убытках.

Ставка дисконтирования влияет на оценку денежных потоков по исполнению обязательств. Отразить это изменение можно следующими способами:

- как инвестиционный результат в отчете о прибылях и убытках;

- как прочий совокупный доход.

Отразить изменение величины корректировки с учетом риска можно так:

- если изменение произошло в текущем или прошлом периодах - в составе прибыли и убытка;

- если изменения относятся к будущим услугам - за счет контрактной маржи по договору.

Итак, страховая компания должна пересматривать оценку денежных потоков по исполнению обязательств в каждом отчетном периоде. Пересмотренные оценки отражаются на контрактной марже по договору, которая признается в составе прибыли или убытка, отражая выполнение обязательств по договору. При этом, разные типы изменений учитываются в составе разных статей финансовых отчетов.

\section{ЛИТЕРАТУРА}

1. MСФО IFRS 17. http://www.minfin.gov.kz

2. Самое важное в измерениях по стандарту IFRS 17 (ч.2). https://gaap.ru/articles/Samoe_vazhnoe_v_izmereniyakh_po_standartu_IFRS_17_ch_

3. Признание контрактной маржи в прибылях и убытках. https://gaap.ru/articles/Priznanie_kontraktnoy_marzhi_v_pribylyakh_i_ubytkakh Опубликовано: 9 марта 2018

4. Новый стандарт по учету договоров страхования: MCФO (IFRS) 17 URL: https://home.kpmg.com/ru/ru/home/insights/2017/05/insurance-contracts-new-standard-firstimpressions-ifrs17-ifrs4-180517.html 